DOSSIÊ TEMÁTICO: Política de Educação Superior

do1 https://doi.org/10.22481/praxisedu.v16i41.7258

\title{
O ACESSO DE ESTUDANTES COM DEFICIÊNCIA NO ENSINO SUPERIOR E SUA RELAÇÃO COM O PROJETO DE SOCIEDADE EXISTENTE
}

\author{
THE ACCESS OF STUDENTS WITH DISABILITIES IN HIGHER EDUCATION AND \\ ITS RELATION WHITH THE EXISTING SOCIETY PROJECT
}

EL ACCESO DE LOS ALUMNOS CON DISCAPACIDAD EN LA EDUCACIÓN

SUPERIOR Y SU RELACIÓN CON EL PROYECTO DE SOCIEDAD EXISTENTE

\author{
Marinalva Silva Oliveira \\ Universidade Federal do Rio de Janeiro - Brasil \\ Sandra Cordeiro de Melo \\ Universidade Federal do Rio de Janeiro - Brasil \\ Maria do Carmo Lobato da Silva \\ Universidade Federal de São Carlos - Brasil
}

\begin{abstract}
Resumo: Este artigo, de caráter ensaístico, tem por objetivo discutir sobre o acesso ao ensino superior às pessoas com deficiências no Brasil. Discute sobre as barreiras existentes no acesso, permanência e conclusão do curso pleiteado, a proporção de menos de $0,5 \%$ de estudantes com deficiência no Ensino Superior, e sobre a cultura do capacitismo que submete as pessoas com deficiência à falsa a concepção de igualdade de oportunidades. Este artigo discute ainda a implantação do Decreto ${ }^{\circ} 9.034 / 17$, em que o Governo Federal altera as regras do programa de cotas dos Institutos e Universidades Federais e inclui pessoas com deficiência na lista de estudantes com direito à reserva de vagas nessas instituições. Considera que, com relação à abertura das IFES é fundamental que estas organizem esforços para a garantia da acessibilidade e da permanência das pessoas com deficiência, com direito à apropriação do conhecimento universal e científico ao longo do processo de estudos. Seguindo esta compreensão, este artigo propõe que os espaços que se baseiam numa materialidade inclusiva constituem mais um instrumento contra hegemônico de luta, para a construção de ambientes favoráveis à consecução de igualdade de condições e oportunidades para acessibilidade do conhecimento historicamente produzido às pessoas com deficiência. Alerta para o fato de que será preciso compreender que, as dificuldades em relação à contradição inclusão e exclusão extrapola a questão da deficiência, pois entende que a relação direta é com o projeto societário existente.
\end{abstract}

Palavras chave: Educação inclusiva; Ensino superior; Sociedade

Abstract: This article, of an essyistic character, aims to discuss the access to Higher Education for people with disabilities in Brazil. It discusses the existing barriers to the access, the permanence and the conclusion of the demanded course as well as the proportion of less than half per cent of students 
with disabilities in Higher Education. It also debates the culture of 'ability' which submits disabled people to the false conception of equality of opportunities. In addition, the present paper discusses the implementation of the Decree Number 9,034/2017 in which the Federal Government changes the rules of the quota program of Federal Universities and Institutes and includes people with disabilities in the list of students entitled to places in these institutions. In relation to the opening of the Federal Institutions of Higher Education this article considers it crucial that they organize efforts to guarantee the accessibility and the staying of disabled people who have a right to the scientific and universal knowledge appropriation throughout their studying process. Along with such understanding this paper proposes that the spaces which are based on an inclusive materiality constitute one more counterhegemonic instrument of struggle for building favorable environments in order to achieve equality of conditions and opportunities for knowledge accessibility historically produced for disabled people. Finally it alerts to the fact that it will be necessary to understand that the difficulties related to the inclusion and exclusion contradiction extrapolates the issue of disability since it perceives that the direct relationship is towards the existing society project.

Keywords: Inclusive Education; Higher Education; Society

Resumen: Este artículo, es de carácter ensayístico, tiene como objetivo discutir sobre el acceso, a la enseñanza superior para las personas con discapacidades en Brasil. Discute, sobre los obstáculos que existen en el acceso, permanencia y conclusión del curso propuesto, con la proporción de menos de $0,5 \%$ de estudiantes con discapacidad en la Educación Superior, y sobre la cultura de capacidad que somete a las personas con discapacidad, a una falsa concepción de una igualdad con oportunidades. Este artículo discute aún la implementación del Decreto de $n^{\circ}$ 9.034/17, en el que el Gobierno Federal, modifica las normas del programa de cuotas de los Institutos y Universidades Federales, e incluye personas con discapacidad en la lista de estudiantes con derecho a la reserva de vagas en estas instituciones. Considera que, con respecto a la apertura de las IFES, es fundamental que estas organicen esfuerzos, para garantizar la accesibilidad y la permanencia de las personas con discapacidad, con derecho a la apropiación del conocimiento universal y científico, a largo del proceso de los estudios. Siguiendo esta comprensión, este artículo propone, que los espacios que se basan, en una materialidad incluyente constituyan un instrumento más contrahegemónico de lucha, para la construcción de ambientes favorables, a la realización de igualdad de condiciones y oportunidades, para la accesibilidad del conocimiento que es históricamente producido para las personas con discapacidad. Alerta para el hecho, de que será necesario entender que las dificultades con respecto, a la contradicción inclusión y exclusión, que extrapola a la cuestión de la discapacidad, pues se entiende que la relación directa es como un proyecto de sociedad vigente.

Palabras clave: Educación inclusiva/incluyente; Enseñanza/ Educación superior; Sociedad

\section{Introdução}

Desconfiai do mais trivial, na aparência singelo. E examinai, sobretudo, o que parece habitual. Suplicamos expressamente: não aceiteis o que é de hábito como coisa natural, pois em tempo de desordem sangrenta, de confusão organizada, de arbitrariedade consciente, de humanidade desumanizada, nada deve parecer natural, nada deve parecer impossível de mudar. (BRECHT, 1966, p. 18).

O debate das políticas educacionais inclusivas está diretamente imbricado na forma como o Estado se articula e mantém o projeto societário hegemônico atual. No mesmo 
sentido, os desdobramentos para a Educação das pessoas com deficiência no Ensino Superior ocorrem no âmbito de disputas de diferentes projetos educacionais e correlações de forças sociais. Desse modo, no bojo das relações que permeiam o projeto societário capitalista e suas estratégias de manutenção faz-se necessário compreender as condições históricas em que as políticas educacionais têm se estruturado e se legitimado nos âmbitos social, ético-político e ideológico para atender ao interesse hegemônico do capital.

Neste âmbito, as políticas que acompanham a materialização da Educação Inclusiva também resultam de embates e conflitos de várias forças sociais e econômicas e de diferentes projetos educacionais em constante disputa, e, portanto, marcada por contradições. Nessa contradição, inclusão $x$ exclusão, pertinentes a um modelo societário estruturalmente excludente, é possível perceber que os discursos hegemônicos vêm se concretizando nas Políticas e Legislações Educacionais inclusivas para pessoas com deficiência. Sob a égide material da exclusão, os desafios para as Instituições de Ensino Superior (IES) assumirem uma postura institucional inclusiva em suas culturas, políticas e práticas não são pequenos e nem passageiros.

O acesso ao Ensino Superior para pessoas com deficiência no Brasil ainda é recente devido às dificuldades enfrentadas por esse público em todo seu processo de escolarização desde o ensino básico, com barreiras existentes no acesso, na permanência e na conclusão do curso (BRITO; QUIRINO; PORTO, 2013; ROCHA; MIRANDA, 2009). A proporção é de menos de 0,5\% de estudantes com deficiência no Ensino Superior e, na sua ampla maioria, são estudantes com deficiência visual, auditiva ou física, além de raríssimos casos de alunos com deficiência intelectual.

Em 2016, foram registradas 1.249.324 matrículas nas 107 Instituições Federais de Ensino Superior, segundo relatórios do Instituto Nacional de Estudos e Pesquisas (INEP) (2014, 2016, 2017), representando 0,93\% do total. Houve um crescimento de matrículas de alunos com deficiência na rede federal de 2014 para 2016 em torno de 9,88\%, entretanto de 2016 para 2017, ocorreu uma diminuição no número de matrículas em torno de 8,43\% (OLIVEIRA, 2019).

A luta pelos direitos das pessoas com deficiência à educação é recente e somente a partir da década de 1980, com os esforços de vários movimentos sociais para a elaboração da Constituição Federal de 1988 tem destaque a luta pelo direito à educação (BRASIL, 1988), e é nesse cenário que as Políticas de Educação Especial têm sido elaboradas sob as pressões de diferentes segmentos sociais (KASSAR; REBELO; OLIVEIRA, 2019). 
As legislações existentes, como a Constituição Federal em seus artigos 208 e 227 (BRASIL, 1988), a Lei de Diretrizes e Bases da Educação Nacional, n 9394/96 (BRASIL, 1996) e mesmo políticas e legislações mais específicas ${ }^{1}$ versam sobre a criação de programas de prevenção e atendimento especializado às pessoas com deficiência física, sensorial ou intelectual, garantindo-lhes adequação curricular, métodos, técnicas e recursos educacionais. Contudo, apesar da obrigatoriedade legal, as Instituições de Ensino Superior, na sua maioria, não têm oferecido condições de acessibilidade e permanência às pessoas com deficiência (PCD).

Segundo Dussilek e Moreira (2017), por mais que as políticas públicas assegurem ao estudante com deficiência o direito ao acesso no Ensino superior, há um descompasso entre o que essas propostas anunciam e a realidade dos estudantes, quanto à permanência e à conclusão da sua formação. As diretrizes legais para acesso e permanência dos estudantes não são aplicadas e as principais causas estão relacionadas ao despreparo dos professores, à falta de conhecimento da população universitária, às implementações de estratégias pedagógicas e às limitações das infraestruturas. No geral, os estudantes com deficiência estão insatisfeitos com as ações e com as condições ofertadas pelas instituições de ensino (CRUZ; VIANNA, 2019).

Torres, Calheiros e Santos (2016) realizaram um levantamento de produção de artigos científicos sobre inclusão na educação superior brasileira com análise da produção científica e os resultados apresentados mostram ações que deveriam ser de responsabilidades das IES, na verdade são assumidas pelas famílias dos estudantes com deficiência para conseguirem permanecer na Universidade. E mais, ainda dependem do estímulo e empatia dos docentes e colegas de turma como fundamentais para sua permanência.

Os estudantes com deficiência enfrentam barreiras arquitetônicas e humanas que são desfavoráveis à sua inclusão no Ensino Superior, tanto no seu ingresso quanto na sua permanência. Logo a questão da acessibilidade é apontada como fundamental para que se possa criar, gerenciar e oferecer condições pedagógicas e instrumentais que favoreçam as pessoas com deficiência no acesso aos ensinamentos pedagógicos (ALMEIDA; BELLOSI; FERREIRA, 2015).

A ausência de acessibilidade no Ensino Superior tem gerado uma situação difícil, cujo resultado tem sido a evasão destes estudantes, salvo para aqueles que trilham o árduo 
caminho da persistência individual. Mesmo assim, o número de estudantes com deficiência inseridos nas IES tem aumentado consideravelmente. No entanto, eles continuam sem encontrar precárias condições de acessibilidade ao conhecimento acadêmico e poucos subsídios que garantam condições adequadas para a conclusão com sucesso do curso (OLIVEIRA, MANZINI, 2008; SOUZA, 2010). Para Oliveira e Manzini (2008), o acesso e permanência implicam em processos de transformação, concomitante com criação de condições legais e institucionais para a garantia de direitos.

Com relação ao ingresso no Ensino superior, as IES estão cumprindo seu papel social quando recebem estudantes com deficiência tanto física e intelectual, quanto sensorial. Contudo esta ação se torna paradoxal quando estas mesmas instituições parecem não viabilizar o acesso tanto à comunicação quanto ao espaço físico e aos equipamentos, contribuindo para um contexto favorável à exclusão destes alunos do processo de produção e socialização do conhecimento. Assim, a inclusão dos estudantes com deficiência no Ensino Superior se apresenta como um processo importante, mas ainda embrionário, exigindo um compromisso com a acessibilidade mediante a supressão constante de barreiras tanto de caráter arquitetônico, pedagógico, comunicacional quanto atitudinal (DISCHINGER; MACHADO, 2006; CASTRO; ALMEIDA, 2014).

Pacheco e Costas (2006) consideram que os estudos realizados sobre o acesso e permanência dos estudantes com deficiência nas Instituições Federais de Ensino Superior (IFES) demonstram que são isoladas e insuficientes as iniciativas de proporcionar a eles apoio psicopedagógico, condições de acessibilidade dentre outros aspectos, necessários ao atendimento das demandas existentes.

Nas IFES, foi apenas em 2005, por meio dos editais do Programa de Acessibilidade ao Ensino Superior - foi lançado o programa Incluir, em parceria com a Secretaria de Educação Superior (SESu) e da Secretaria de Educação Continuada, Alfabetização, Diversidade e Inclusão (SECADI), com o objetivo de possibilitar a acessibilidade nas IES públicas, para assim ter acesso aos poucos recursos para a estruturação de Núcleos de Acessibilidade (COSTA; FANTACINI e LESSA, 2018; SIQUEIRA; SANTANA, 2010; NOZU; BRUNO; CABRAL, 2018). Estes núcleos visam a garantia da inclusão de pessoas com deficiência à vida acadêmica, buscando eliminar barreiras físicas, pedagógicas, arquitetônicas, na comunicação e informações, nos ambientes, instalações, equipamentos e materiais didáticos. 
Apesar da obrigatoriedade legal, as IFES na sua maioria, não possuíam Núcleo de Atendimento Educacional, pois os recursos governamentais eram escassos e não atendiam a demanda de criar, gerenciar e oferecer condições pedagógicas e instrumentais para que os estudantes com deficiência pudessem ter acesso ao conhecimento científico. Isto tem gerado um processo de inclusão precário ou uma "inclusão excludente", dado que, mesmo o pequeno número de alunos com deficiência não tem encontrado condições para seu desenvolvimento acadêmico.

Em 2016 com a Lei de Cotas, $n^{\circ} 12.711 / 2012$, o governo federal alterou as regras do programa de cotas dos Institutos e Universidades federais e incluiu pessoas com deficiência na lista de estudantes que têm direito à reserva de vagas nessas instituições (Decreto $\mathrm{n}^{\circ}$ 9.034/17). O decreto é um avanço e fruto da luta dos movimentos sociais, dado que a educação deve ser um lugar para todos. No entanto, na perspectiva da educação como um direito, não basta apenas garantir o acesso ao espaço físico nos IES, mas também a acessibilidade e a permanência das pessoas com deficiência com direito a apropriação do conhecimento universal e científico ao longo do processo de estudos.

Seguindo esta compreensão, os espaços que se baseiam numa materialidade inclusiva constituem mais um instrumento contra hegemônico de luta, para a construção de ambientes favoráveis à consecução de igualdade de condições e oportunidades para acessibilidade do conhecimento historicamente produzido às pessoas com deficiência. Desse modo, as dificuldades em relação à contradição inclusão e exclusão extrapola a questão da deficiência, dado que a relação direta é com o modelo de sociedade existente.

Para aprofundar a compreensão de como está sendo efetivado o processo de inclusão no Ensino Superior de pessoas com deficiência no contexto das políticas educacionais, elaboradas numa cultura de maximização da produção e do lucro, será necessário compreender como estas pessoas com deficiência são concebidas nesse processo. Para isso, procura-se destacar que a percepção da deficiência pela sociedade é formada a partir dos valores ideológicos da classe hegemônica, para o cumprimento de seus objetivos, para a conquista e a manutenção das relações de dominação, afastando aqueles que não atendam às suas demandas, os improdutivos.

As pessoas com deficiência, ao longo de sua história de lutas e resistências, sempre foram vistas pelo que não poderiam fazer. Portanto, a não participação na geração do lucro capitalista resulta nos mais variados processos de exclusão, contribuindo para a eliminação de quaisquer possibilidades de se realizarem ontologicamente por meio do trabalho. As barreiras 
impostas às pessoas com deficiência ao acesso à Educação Superior têm relação com a imposição de uma sociedade que os elimina e se fundamenta na cultura do capacitismo, na qual as pessoas com deficiência são vítimas, sendo perversa a concepção de igualdade de oportunidades para todos, o que acaba por responsabilizar a pessoa pelo seu sucesso ou fracasso na sociedade. Este discurso desconsidera as bases materiais que promovem desigualdades de apropriação e usufruto das produções humanas (GARCIA, 2016).

Nessa lógica de exclusão, as pessoas com deficiência constituem-se em sinônimo de ineficiência, improdutividade, consideradas incapazes de contribuir nessa sociedade, que têm suas relações definidas pela produção e pelo lucro. Isso acarreta práticas injustas e discriminatórias, que têm como consequência o estabelecimento de limites. Esses limites impossibilitaram, por anos, que pessoas com deficiência tivessem condições de lutar, em igualdade, por direitos na sociedade.

Quando se trata da Educação Inclusiva, as experiências que se propõem a ir além do que é exigido pelo "capital" também são dificultadas pela forma como a sociedade compreende o desenvolvimento das pessoas com deficiência, quando desconsidera que as leis responsáveis pelo desenvolvimento de uma pessoa com deficiência sejam as mesmas que regem o desenvolvimento de pessoas sem deficiência (VIGOTSKI, 1997). Isso tem como consequência, no processo de inclusão de um modo geral e, mais especificamente no caso das pessoas com deficiência, a prática do princípio da "normalização", quando o reduzido número de pessoas que chegam ao Ensino Superior tem a obrigatoriedade de se adaptarem às metodologias e estratégias utilizadas, cuja maioria segue a concepção meritocrática e normalizadora, na qual a pessoa é percebida por suas capacidades individual e intelectual e condição de produtividade numa lógica padronizada.

Assim a educação concebida às pessoas com deficiência no Ensino Superior não rompeu com a visão biologizante da deficiência e com as práticas justificadoras do "fracasso das pessoas", uma vez que dentro das universidades permanece a divisão entre educação na sala de aula e atendimento especializado nos núcleos, como forma suplementar ou complementar para "eliminar" barreiras no processo de ensino, aprendizagem e participação social. A primeira questão que se coloca é: se a educação é inclusiva, por que precisa de educação complementar ou suplementar? A segunda: se é educação inclusiva, por que o termo assume significado ao se restringir a um grupo específico de pessoas, aquelas com deficiência? Esse discurso é parte integrante da sociedade capitalista marcada, hegemonicamente, por uma educação restrita e excludente. 
Para Garcia (2016), a ideia de que a inclusão ocorrerá somente ao eliminar as barreiras de aprendizagem expressas nos objetivos do atendimento especializado coaduna com os propósitos da visão capitalista de "inclusão" e "conformidade" ao estabelecido. Destarte, tem-se a falsa aparência que a organização social em curso e os processos educacionais a ela relacionados são exitosos, bastando garantir o ingresso destas pessoas no Ensino Superior e sendo suficiente a criação de medidas, em alguns casos imediatistas e paliativas, de ajustes para o acesso a aprendizagem. Isso apenas contribui para desfocar a atenção das questões sociopolíticas e culturais a serem compreendidas e tratadas coletivamente. Apropriar-se dos significados das palavras é importante, pois revela a relação do indivíduo entre aquilo que o incita a agir, e aquilo para o qual a sua ação se orienta como resultado imediato (LEONTIEV, 2004; 2005).

O processo de inclusão das pessoas com deficiência na Educação Superior depende de transformações que eliminem barreiras, reconstruam concepções e práticas que segregam e excluem. É preciso romper com tudo que obstrua sua participação plena e efetiva na sociedade em igualdades de condições com as demais pessoas. Diante desse conceito, a deficiência passa a ser vista como consequência e não como causa das barreiras existentes na sociedade.

Neste sentido, as adequações das estruturas arquitetônicas, a eliminação das barreiras pedagógicas, de comunicação e de informação, e o desenvolvimento de uma cultura de inclusão, na qual esforços são direcionados para ressignificar atitudes, conceitos e concepções sobre as deficiências, mostram-se como maneiras mais contundentes de possibilitar a inclusão das pessoas com deficiência no Ensino Superior.

Não há dúvida de que precisamos romper com a cultura do capacitismo tão presente como forma de discriminação e opressão das pessoas com deficiência. Os discursos e práticas que envolvem o capacitismo e a discriminação revelam uma normatividade opressora, que invisibiliza, oprime, oculta a representatividade de quem não se enquadra no "sujeito universal" (MELLO, 2016). Tais discursos e práticas nessa ótica do capacitismo têm a tendência de achar que a "não deficiência" é o "normal" e que pessoas que têm deficiência precisam se virar para se encaixar numa normatividade padrão. Ou seja, é uma forma discriminatória de considerar as pessoas com deficiência como inferiores, subalternas; tal atitude equivale a mesma cultura opressora e discriminatória como o machismo, racismo e homofobia (MELLO, 2016). 
Siqueira e Santana (2010) ressaltam que a inclusão de pessoas com deficiência no Ensino Superior não pode ser pensada a partir de ações isoladas, mas precisa congregar ações com vistas à aquisição de produtos e tecnologias; ações voltadas às atitudes sociais e para as políticas de inclusão de ingresso e permanência, assim como relativas ao apoio que as instituições de ensino necessitam no âmbito das pesquisas que desenvolvem, no financiamento da infraestrutura voltadas à formação e para o ensino, entre outros.

As condições materiais estão postas por um sistema que reconhece através de seus aparelhos de legitimação, a condição de sujeito - ainda não incluído. Destarte, a única alternativa parece ser provocar a ruptura com o paradigma social existente e substituí-lo por outro que seja estruturalmente inclusivo, para que não seja preciso existir políticas protecionistas específicas para cada grupo ou sujeito, pois a todos serão garantidos e efetivados os direitos sociais.

A política educacional brasileira e seus desdobramentos para a inclusão educacional propõem-se a atender as populações consideradas - excluídas ou - marginalizadas nos diferentes níveis e modalidades de ensino. No entanto, é preciso esclarecer que tais políticas de inclusão não superam as condições em que se produz a exclusão, na medida em que não desestruturam ou rompem com o modo de produção capitalista, mas apenas colaboram para o — ajuste ou — acomodação, ou ainda buscam a conciliação da relação entre capital e trabalho (KASSAR, 2003; NEVES, 2005; MÉSZÁROS, 2005; GARCIA, 2016).

Para Garcia (2016) os mecanismos e estrategias adotadas para evitar e minimizar a exclusão educacional não rompem com os elementos que originam a desigualdade educacional relacionados a ensinar e aprender que, por sua vez, estão enraizadas à lógica social vigente.

\section{Experiência da Universidade Federal do Rio Janeiro no processo de Inclusão de estudantes com deficiência}

Como duas das autoras do presente artigo são professoras efetivas da Universidade Federal do Rio de Janeiro (UFRJ), optamos por apresentar a experiência desta universidade no que diz respeito ao desenvolvimento de políticas institucionais de inclusão no âmbito do Ensino superior.

De acordo com Santos e Melo (2019), na Universidade Federal do Rio de janeiro, motivada pelo já citado Programa Incluir (2005): 
[...] cerca de vinte grupos de pesquisa e extensão foram convidados a participarem desta movimentação, que culminou na criação, em 2007, de uma divisão de inclusão e acessibilidade vinculada à Pró-reitoria de Graduação. Esta divisão perdurou por alguns anos, mas sendo liderada por apenas uma técnica e sem outros aportes da universidade. $\mathrm{O}$ orçamento obtido pela participação da referida universidade nos editais do Programa Incluir era o que garantia as ações de acessibilidade na universidade, e tal orçamento sempre ficou muito aquém das necessidades da universidade como um todo.

Segundo as autoras, em 2015 uma nova tentativa de mobilização foi feita e deu origem ao Fórum Permanente Universidade Acessível e Inclusiva (FPAI) com o objetivo de construir e discutir pautas referentes às questões sobre acesso e permanência, não apenas de estudantes, mas de toda a comunidade acadêmica com deficiência.

Com a implantação da Lei 13.409, de 28 de dezembro de 2016, o FPAI percebeu que:

[...] apenas construir as pautas e discuti-las não seria suficiente. Era preciso se garantir uma instância executiva voltada para a acessibilidade. Assim, como fruto da luta levada a cabo pelo Fórum em 2017, em 22 de fevereiro de 2018, a comunidade com deficiência da universidade, por meio do FPAI, conseguiu que o gabinete do reitor criasse uma nova Diretoria, uma instância executiva, vinculada diretamente à reitoria: a Diretoria de Acessibilidade DIRAC. (SANTOS; MELO, p. 10, 2019).

A Diretoria de acessibilidade (DIRAC) tem por objetivo construir políticas institucionais de acessibilidade e inclusão, com foco na inclusão de pessoas com deficiência, no âmbito da universidade. Sobre o papel desta diretoria, as autoras salientam que:

[...] a DIRAC tem um papel tanto executivo quanto educativo. Executivo, no sentido de dar andamento às diretrizes desejadas pela Reitoria em termos de acessibilidade, assim como de dar encaminhamento às demandas de acessibilidade levadas à DIRAC pelo FPAI perante a gestão superior da universidade. $\mathrm{O}$ caráter educativo de suas ações reside no fato de que seria impossível uma administração central, sozinha, responsabilizar-se pela promoção da acessibilidade em uma instituição de tal monta. Ademais, sempre convém lembrar que inclusão é e deve ser assunto de todos, e não apenas de algumas instâncias institucionais ou estatais. (SANTOS; MELO, p.10, 2019).

Esta experiência mostra que o trabalho em prol da inclusão de estudantes com deficiência no Ensino Superior demanda esforço contínuo e amplo, implicando igualmente as instâncias executivas e educativas da instituição. Uma instância como a DIRAC na UFRJ assegura o alcance institucional para a construção, supervisão e acompanhamento de políticas que favoreçam o desenvolvimento de culturas e a orquestração de práticas mais inclusivas. A 
manutenção do FPAI congrega as demandas locais e as produções de grupos de pesquisa e extensão, atualizando a instituição de suas questões relativas à sua comunidade com deficiência. Outro aspecto importante é que, mesmo com a DIRAC e com o Fórum, muito ainda há para fazer considerando a enormidade de demandas da Universidade.

No âmbito da Faculdade de Educação da UFRJ, a partir da alteração da Lei 12.711/2012 em 2016, autorizando que pessoas com deficiência tivessem acesso à Universidade pública por meio da reserva de vagas, alguns estudantes com deficiência vêm ingressando, dentre eles aqueles com deficiência visual, auditiva e intelectual. Observando os estudantes, considerando aqueles sem deficiência, percebemos que estes têm se mostrado apoiadores do processo de adaptação e inclusão de seus colegas com deficiência. Não é raro passar pelo campus e observar estudantes videntes auxiliando estudantes com deficiência visual a chegarem em suas salas de aulas, amizades formadas entre estudantes com e sem deficiência, estudantes do curso de Língua Brasileira de Sinais (LIBRAS), auxiliando a comunicação de estudantes com deficiência auditiva em sala de aula, além do acolhimento de estudantes com deficiência intelectual.

Contudo, observando os professores, percebemos em relatos proferidos em reuniões colegiadas, que há um enorme desconforto com a presença de estudantes com deficiência em sala de aula. Falas do tipo: "Eu não estou preparada para lidar com alunos surdos!", ou "Aquela aluna está sempre interrompendo a minha aula!" (referindo-se à estudante com deficiência intelectual), ou ainda "Faço o que eu posso para adaptar a minha aula, mas não tenho recursos para ajudá-lo mais!" (referindo-se ao estudante com deficiência visual). Estas falas demonstram um sentimento de despreparo para atuar com estudantes com deficiência, o que há muito tempo é sentido pelos professores da escola básica, e agora reverbera nas falas dos professores universitários. De acordo com Santos e Melo (p. 829, 2019),

No cenário brasileiro, a educação básica clama por atenção, em todos os níveis, mas principalmente no que diz respeito aos processos desencadeados por leis específicas sobre inclusão em educação. Contudo, mesmo este cenário de despreparo parece mais preparado quando se coloca em vista a educação superior. Historicamente, as escolas vêm trabalhando com alunos com deficiência, transtornos e mesmo dificuldades de aprendizagem há muito tempo, mas as universidades estavam, neste sentido, reservadas àqueles sem quaisquer problemas de aprendizagem, aos brancos, aos possuidores de condições para concluir um curso universitário.

A Faculdade de Educação (FE) da UFRJ é responsável pelos cursos de graduação em Pedagogia e de pelo menos 15 Licenciaturas, inclusive a do curso de Letras com ênfase em LIBRAS. À FE da UFRJ estão reservadas as disciplinas de Psicologia da Educação, 
Sociologia da Educação, Filosofia da Educação, Didática, Educação Brasileira, Didática Especial, e Prática de Ensino e Estágio Supervisionado. Especialmente no curso de LIBRAS, a maioria das matrículas são de estudantes surdos, fato que requer adaptações em todas as disciplinas.

Neste sentido, visando favorecer o desenvolvimento dos alunos surdos, o curso de Letras oferece encontros de discussão sobre a temática. Como nem todos os professores podem ou querem participar destes eventos, tais orientações chegam em forma de "dicas" que os professores participantes oferecem àqueles que não participam, nas ditas reuniões colegiadas. Presenciamos muitas destas "trocas" nas quais professores orientavam seus colegas, em turmas com alunos surdos, a trabalharem com textos menores, explorarem os resumos, e a utilizarem de imagens como estratégias pedagógicas.

O que vem sendo exposto até agora são apenas exemplos da forma como está ocorrendo a participação dos estudantes com deficiência no espaço da educação superior. Os desafios para Universidades e Institutos Federais assumirem uma orientação inclusiva em suas culturas, políticas e práticas pedagógicas e institucionais, não são pequenos, pois de modo geral, ainda faz parte da cultura buscar as explicações das dificuldades acadêmicas de muitos estudantes como resultante de lesões e limitações pessoais, referindo-se ao enfoque biomédico que responsabiliza a pessoa por suas dificuldades.

A educação inclusiva numa perspectiva emancipatória, por outro lado, assume-se como respeitadora da cultura, da capacidade, potencialidades e das possibilidades de evolução de todos os estudantes. Compreende o espaço acadêmico como comunidade educativa e defende um ambiente de aprendizagem diferenciado e de qualidade para todos os estudantes. Desta forma, reconhece as diferenças, trabalha com elas para o desenvolvimento e dá-lhes um sentido.

\section{Considerações finais}

A inclusão dos estudantes com deficiência no Ensino Superior decorre das possibilidades de estes conseguirem progressos significativos nos seus processos de desenvolvimento acadêmico-científico, e isso poderá ocorrer quando a Universidade assumir que as dificuldades de alguns estudantes não são apenas deles, mas resultam, em grande parte, dos modos como o ensino é ministrado, a aprendizagem é concebida e avaliada. Inclusão 
como se pode ver, não é um fato, é um processo. E, como todo processo, tem suas etapas e deve ser avaliada crítica e responsavelmente para sua própria qualificação.

Desse modo, o motivo que sustenta a luta pela inclusão como uma nova perspectiva para as pessoas com ou sem deficiência é, sem dúvida, a qualidade de ensino em todos os níveis de ensino, de modo que se tornem aptos para responder às necessidades de cada um, de acordo com suas especificidades, sem cair nas teias da escola especial e suas estratégias de exclusão.

Os discursos hegemônicos de inclusão têm como propósito direcionar o debate sobre políticas de inclusão educacional para o - está ou - não está incluído/inserido na Universidade, desfocando o debate sobre o que tem sustentado historicamente a exclusão social - o modo de produção capitalista. Todavia, na medida em que são necessários muitos embates e enfretamentos para romper com a lógica capitalista, faz-se necessário criar oportunidades de acesso e apropriação de conhecimentos pelas pessoas com deficiência que estão no Ensino Superior. Uma dessas proposições é pressionar o Estado a criar condições de acesso ao conhecimento para que essas pessoas tenham possibilidades de se apropriarem da cultura e dos bens sociais como direito social.

As condições de acesso, permanência e apropriação de conhecimentos por estudantes com deficiência no Ensino Superior perpassam por questões mais amplas como a reestruturação da Universidade, financiamento público, políticas institucionais de acesso e permanência dos estudantes, formas de ensinar e conceber esses estudantes, além do processo de identificação desses estudantes, formação inicial e continuada de professores e profissionais, condição de trabalho, condição salarial, rede de serviços e apoios entre outros.

Para Anache et al (2014) além dos fatores já apontados acima há questões mais pontuais que podem contribuir para a construção de uma cultura inclusiva no contexto universitário como: a sensibilização da comunidade universitária, pesquisas sobre concepções de estudantes, professores e técnicos acerca da inclusão; atividades de ensino, pesquisa e extensão; criação de estágios supervisionados; construção de instrumentos de triagem e avaliação para registro, atendimento e acompanhamento dos acadêmicos que procuram o atendimento educacional especializado; avaliação das necessidades educacionais dos estudantes; orientação ao corpo docente e funcionários de diferentes setores da instituição; diagnóstico institucional sobre as condições de acessibilidade; proposição e criação de uma unidade institucional para garantir a efetivação das políticas de inclusão na Universidade. 
As críticas aqui lançadas não conduzem ao imobilismo ou à conformação, mas estão no sentido de continuidade de mobilização e luta por uma Educação e uma Sociedade inclusiva. Todavia, é preciso que se tenha a convicção de que as atuais Políticas da Educação Inclusiva nos mais diferentes níveis e modalidades de ensino não desestruturam o sistema capitalista, uma vez que são estratégicas para sua própria manutenção.

$\mathrm{Na}$ perspectiva social da deficiência, o problema central do "déficit" está na sociedade capitalista/burguesa que exclui, oprime e se mantém, hegemonicamente, pela desigualdade social. É a estrutura social que desabilita e cria condições de deficiência devido a falta de serviços e oportunidades adequadas para garantir a plena e incondicional inclusão social de todos. Neste aspecto, a deficiência não é uma consequência natural do corpo lesionado, e sim uma imposição econômica, política, cultura e social.

É importante considerar em nossas reflexões, que o déficit orgânico não pode ser ocultado ou minimizado, visto que estão presentes e podem provocar grandes desafios na vida dessas pessoas, no entanto, o que está em nossa lente de aumento é a opressão sobre a condição de vida concreta que delimita a deficiência. Desse modo, qualquer que seja a natureza ou causa da deficiência, os principais desafios a serem enfrentados residem na qualidade das interações e relacões com o ambiente e rupturas com múltiplas barreiras insensíveis a diversidade humana, a citar, desde barreiras atitudinais, políticas, comunicacionais, físicas e arquitetônicas que favorecem e sustentam a cultura do capacitismo sobre as pessoas com deficiência.

\section{REFERÊNCIAS}

ALMEIDA, José Guilherme Andrade; BELLOSI, Tereza Cristina; FERREIRA, Eliana Lúcia. Evolução da matrícula de pessoas com deficiência na educação superior brasileira: subsídios normativos e ações institucionais para o acesso e permanência. Revista Ibero-americana de estudos em Educação, v.10, p.643-660, 2015.

ANACHE, Alexandra Ayach; ROVETTO, S.S.M; OLIVEIRA, R.A. Desafios da implantação do atendimento educacional especializado no Ensino Superior. Revista Educação Especial, v.27, n.49, p.2999-312, 2014.

BRASIL. Constituição (1988). Constituição da República Federativa do Brasil. Brasília, DF, Senado, 1988.

BRASIL. Lei ${ }^{\circ} 13.409$ de 28 de dezembro de 2016. Altera a Lei no 12.711, de 29 de agosto de 2012, para dispor sobre a reserva de vagas para pessoas com deficiência nos cursos técnico de nível médio e superior das instituições federais de ensino. Diário Oficial da União, 
29/12/2016, p. 3. Disponível em:

http://www.planalto.gov.br/ccivil_03/_ato20152018/2016/Lei/L13409.htm . Acesso em: 8 dez. 2019.

BRASIL. Lei Federal n. 9394/96. Estabelece as Diretrizes e Bases da Educação Nacional, Brasília, 1996.

BRASIL. Política Nacional de Educação Especial na Perspectiva da Educação Inclusiva. MEC, SEESP, 2008.

BRASIL. Ministério da Educação. Documento orientador Programa Incluir - Acessibilidade na Educação Superior. Secadi/Sesu-2013. Brasília/DF, 2013. Disponível em:

http://portal/mec.gov.br/arquivos/pdf/politicaeducespecial.pdf. Acesso em: 28 de dezembro de 2019.

BRASIL. Lei n ${ }^{\circ}$ 13.146, de 06 de julho de 2015. Institui a Lei Brasileira de Inclusão da Pessoa com Deficiência. Estatuto da Pessoa com Deficiência. Diário oficial da União, Brasília, 7 jul. 2015.

BRASIL. Decreto 9.034 de 20 de abril de 2017. Altera o Decreto ${ }^{\circ} 7.824$, de 11 de outubro de 2012, que regulamenta a Lei ${ }^{\circ} 12.711$, de 29 de agosto de 2012, que dispõe sobre o ingresso nas universidades federais e nas instituições federais de ensino técnico de nível médio. Diário Oficial da União, 24/04/2017, p. 1. Disponível em:

http://www.planalto.gov.br/ccivil_03/_ato2015-2018/2017/decreto/D9034.htm. Acesso em: 28 maio. 2017.

BRECHT, Bertold. Poemas e canções. Rio de Janeiro: Civilização Brasileira, 1966.

BRITO, Angélica Elisabete; QUIRINO, Danielle Lobo da Cunha; PORTO, Lívia Carolina de Medeiros. Educação Especial e Inclusiva no Ensino Superior. Revista Educação, v.16, n.2021, p. 14-20, 2013.

CASTRO, Sabrina. Fernandes., ALMEIDA, Maria Amélia. Ingresso e Permanência de Alunos com Deficiência em Universidades Públicas Brasileiras. Rev. Bras. Ed. Esp., Marília, v. 20, n. 2, p. 179-194, Abr.-Jun., 2014.

COSTA. Maria Vilma Pontes da; FANTACINI, Renata Andrea Fernandes; LESSA, Tatiane Cristina Rodrigues. Inclusão da Pessoa com Deficiência no Ensino Superior: Análise das Produções de 2008 a 2018. Nucleus, v.15, n.2, out. 2018.

CRUZ, Taynara Xavier; SOARES, Wellington Danilo; VIANNA, Raquel Schwenck Mello. Inclusion of People With Disabilities in Higher Education: na Integrative Review. Health and Society Port. J. 4(1): 1062 - 1075, 2019.

DISCHINGER, Marta.; MACHADO, Rosângela. Desenvolvendo ações para criar espaços escolares acessíveis. In: Inclusão, Brasília/DF, vol. 2, n. 2 , p. 33-39, jul., 2006.

DUSSILEK, Carlos Alberto; MOREIRA, Jaqueline Costa Castilho. Inclusion in higher education: a systematic review of the conditions presented to students with disabilities.

Research, Society and Development, v. 6, n. 4, p. 317-341, 2017. 
FERREIRA, Solange Leme. Ingresso, permanência e competência: uma realidade possível para universitários com necessidades educacionais especiais. Revista Brasileira de Educação Especial, v.13, n.1, p.43-60, 2007.

GARCIA, Rosalba Maria Cardoso. Educação Especial na Perspectiva Inclusiva:

Determinantes econômicos e políticos. Comunicações, Piracicaba, v. 23, n. 3, p. 7-26 2016.

KASSAR, Mônica de Carvalho Magalhães; REBELO, Andressa Santos; OLIVEIRA, Regina Tereza Cestari de. Embates e disputas na política nacional de Educação Especial brasileira. Educação e Pesquisa., São Paulo, v. 45, p. 1-19, ago, 2019.

KASSAR, Mônica de Carvalho Magalhães .Políticas Educacionais e Sujeitos: Contribuição para Desenhos de Pesquisa em Educação Especial. Perspectiva, Florianópolis, v. 21, n. 02, p. 413-430, jul./dez. 2003.

LEONTIEV, Alexei. Os princípios do desenvolvimento mental e o problema do atraso mental. In: LURIA, Alexander Romanovich; VYGOSTSKY, Lev Seminovich., et al. Psicologia e Pedagogia: Bases Psicológicas da Aprendizagem e do Desenvolvimento Humano. São Paulo: Centauro, 2005, p. 05-20.

LEONTIEV, Alexis. O desenvolvimento do psiquismo. Tradução Rubens Eduardo Frias, $2^{\text {a }}$ ed. São Paulo: Centauro, 2004.

MELLO, Anahi Guedes de. Deficiência, incapacidade e vulnerabilidade: do capacitismo ou a preeminência capacitista e biomédica do Comitê de Ética em Pesquisa da UFSC. Ciência \& Saúde Coletiva, v. 21, n. 10, p. 3265-3276, 2016.

MÉSZÁROS, István. Educação para além do capital. São Paulo: Boitempo Editorial, 2005.

NEVES, Lúcia Maria Wanderley (Org.). A nova Pedagogia da Hegemonia: Estratégias do Capital para Educar o Consenso. São Paulo: Xamã, 2005.

NOZU, Washington Cesar. Shoiti.; BRUNO, Marilda Moraes Garcia.; CABRAL, Leonardo Santos Amâncio. Inclusão no Ensino Superior: Políticas e Práticas na Universidade Federal da Grande Dourados, Psicologia Escolar e Educacional, São Paulo, v. 22, p. 105-113, 2018. Número Especial. http://dx.doi.org/10.1590/2175-35392018056

OLIVEIRA, Elaine Teresa Gomes.; MANZINI Eduardo José. Acessibilidade na Universidade Estadual de Londrina: O Ponto de Vista do Estudante com Deficiência. In: ALMEIDA, M. A., MENDES, E. G.; HAYASHI, M. C. P. I. Temas em Educação Especial: Múltiplos Olhares. Araraquara: Junqueira\&Marin, p. 220 - 229. 2008.

OLIVEIRA, Jair. Análise da Produção Científica com a Temática Inclusão no Ensino Superior: reflexões sobre artigos publicados no período de 2016 a novembro de 2018. Revista Educação Especial v. 32, Santa Maria, 2019.

PACHECO, Renata Vaz; COSTAS, Fabiane Adela Tonetto. Processo de inclusão de acadêmicos com necessidades educacionais especiais na Universidade Federal de Santa Maria. Revista Educação Especial. Santa Maria, n. 27, p. 151-170, 2006. 
SANTOS, Mônica Pereira dos; MELO, Sandra Cordeiro de Melo. RPGE- Revista on line de Política e Gestão Educacional, Araraquara, v. 23, n. esp. 1, p. 818-835, out. 2019.

SIQUEIRA, Inajara Mills and SANTANA, Carla da Silva. Propostas de acessibilidade para a inclusão de pessoas com deficiência no ensino superior. Revista brasileira de educação especial, vol. 16 n.1, p.127-136, 2010.

SOUZA, V. R. M. A Inclusão do Aluno com Deficiência no Ensino Superior: O Caso da Universidade Federal de Sergipe. In: CONGRESSO BRASILEIRO DE EDUCAÇÃO ESPECIAL. 4., 2010, São Carlos São Carlos. Anais do IV Congresso Brasileiro de Educação Especial. 16p, São Carlos, 2010.

TORRES; Josiane Pereira; CALHEIROS, David dos Santos; SANTOS, Vivian. Inclusão na educação superior brasileira: Análise da produção cientifica. Interfaces da Educação, Paranaíba, v.7, n.19, p.296-313, 2016.

VYGOSTSKY, Lev Semyonovitch. Obras Escogidas: Fundamentos da Defectologia. vol. V. Madrid: Visor, 1997.

\section{SOBRE AS AUTORAS:}

\section{Marinalva Silva Oliveira}

Doutora pela Universidade de São Paulo (USP); Professora Associada IV da Universidade Federal do Rio de Janeiro (UFRJ); Coordenadora do Laboratório de Inclusão, Mediação Simbólica, Desenvolvimento e Aprendizagem (LIMDA) e do Grupo de Pesquisa REPRESENTAÇÃO + INCLUSÃO - reflexões sobre o papel das representatividades no processo de desenvolvimento e aprendizagem de alunos com síndrome de Down e Transtorno do Espectro Autista. E-mail: marinalvaoliveira@yahoo.com.br

iD http://orcid.org/0000-0003-1157-3931

\section{Sandra Cordeiro de Melo}

Pós-Doutorado em Educação (Universidade do Estado do Rio de Janeiro - UERJ); Professora Adjunta, Faculdade de Educação, Universidade Federal do Rio de Janeiro - UFRJ. Coordenadora do Laboratório de Inclusão, Mediação Simbólica, Desenvolvimento e Aprendizagem - LIMDA/FE/UFRJ. E-mail: sandracmello@gmail.com

iD http://orcid.org/0000-0002-8437-1671

\section{Maria do Carmo Lobato da Silva}

Doutoranda em Educação Especial pela Universidade Federal de São Carlos (UFSCAR). Professora do colegiado de Pedagogia na Universidade Federal do Amapá (UNIFAP). Integrante do Grupo de Pesquisa de Formação de Recursos Humanos em Educação Especial pela Universidade Federal de São Carlos (UFSCAR). E-mail: marialobato1607@ gmail.com (iD) http://orcid.org/0000-0003-0185-5329 